\title{
Book Review of An Introduction to the Chemistry of the Sea, 2nd Edition, by Michael E.Q. Pilson
}

\section{Hardcover ISBN-13: 978-0521887076}

\section{Simon Rees}

Teaching Fellow, The Foundation Centre, Durham University

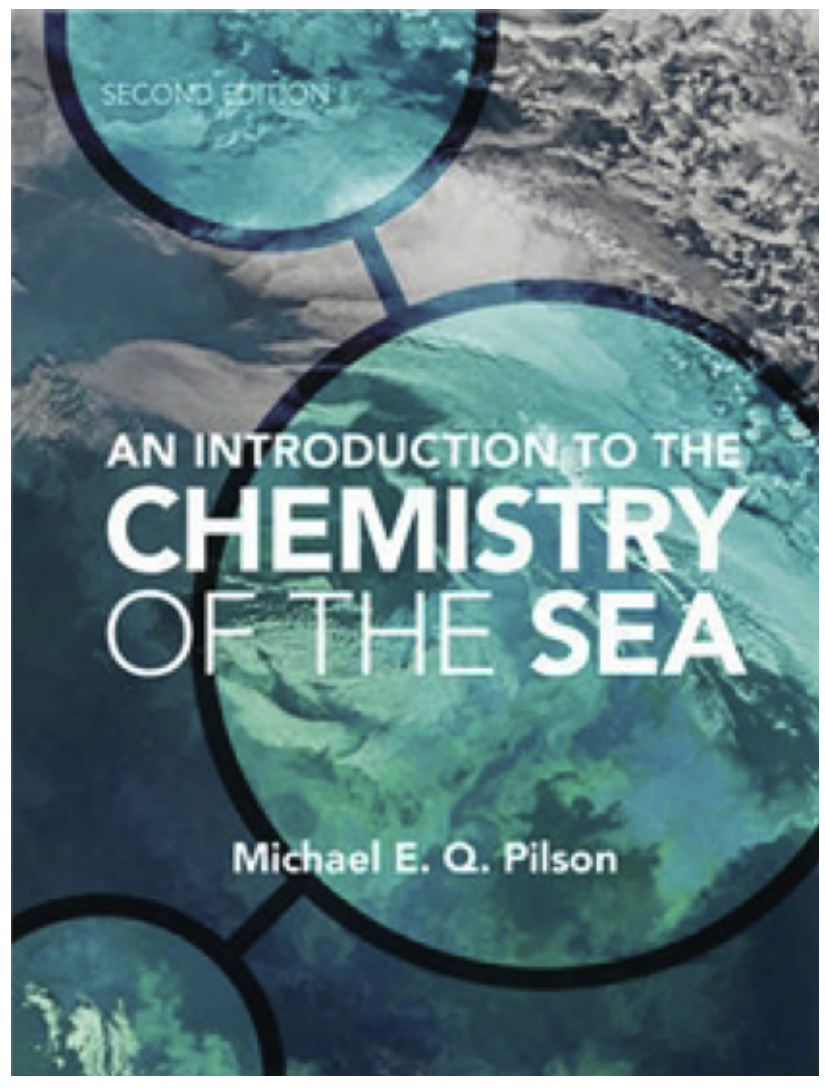

\section{Corresponding author:}

Simon Rees, Teaching Fellow, The Foundation Centre, Durham University

Email: simon.rees@durham.ac.uk
This engaging and comprehensive volume serves as an excellent introduction to this topic for students with a broad range of backgrounds in the physical sciences. The author engages the reader from the start with a succinct and fascinating history of physical oceanography and reminds us of the lasting impact of the H.M.S. Challenger expedition (1873-1876) on this field. This book combines these past achievements with contemporary research to inform the reader with a diverse and comprehensive overview of the chemistry of the sea.

Initial chapters provide a clear account of the physical properties of water, the isotopes of hydrogen and oxygen and conductivity and salinity that would be appropriate to any general chemistry course. This is followed by an explanation of gas behaviour and exchange at the air-sea interface and a discussion of salts in solutions including an interesting section on the absorption of sound. There is a substantial section on carbon dioxide and the ocean's role in its regulation and then significant nutrients (e.g. phosphorus, nitrogen) and minor elements (e.g. mercury and iron) are discussed in turn. Substantial attention is also given to organic matter in the oceans and the formation of anoxic zones. The final chapters of the book focus on exchange at the boundaries of the sea, the chemical extraction of useful substances and the geochemical history of the oceans. 
Each chapter is very clear and well organised with the text supported by a large number of results from the literature presented in tables and graphs. There is a summary box of key points at the start each chapter as well as a summary at the end with further reading. Questions for students to reflect on are provided at the back of the book. It may have been helpful for the reader to have been given some guided prompts/answers to these. The glossary and appendices are useful to explain many of the principles underlying the research discussed in the chapters. These could have been more explicitly linked with the chapters to help guide the reader to an explanation of terminology used in the main text.

The epilogue is a suitably eloquent and thought provoking end to the book with a poem by Lord Byron and the author's reflection on the impact of the human race on the oceans. The author considers that "humans now operate as a geological force" shaping the geochemical flows through the oceans. Given the weight of the evidence presented in this book, one has to be inclined to agree. 